\title{
O instante alinhavado em versos: entrevista com Mônica de Aquino
}

\author{
Letícia Malloy ${ }^{1}$ \\ André Tessaro Pelinser ${ }^{2}$ \\ Vitor $\mathrm{Cei}^{3}$
}

\section{Resumo}

Mônica de Aquino, poeta de Belo Horizonte, tem se destacado no cenário da literatura brasileira contemporânea. Em entrevista concedida a membros do projeto de extensão "Notícia da atual literatura brasileira: entrevistas", queconsiste em mapeamento da literatura brasileira do início do século XXI a partir da perspectiva dos próprios escritores, a poeta discorre sobre seu processo de escrita criativa, avalia a recepção de sua obra e reflete tanto sobre aspectos relativos à literatura brasileira quanto sobre o quadro político e cultural dos últimos anos e as respostas éticas por ele demandadas.

Palavras-chave: Mônica de Aquino; poesia; literatura brasileira contemporânea; literatura infantil brasileira; escrita criativa

${ }^{1}$ Doutora em Estudos Literários (UFMG). Professora da Universidade do Estado do Rio Grande do Norte.

${ }^{2}$ Doutor em Estudos Literários (UFMG). Professor do Programa de Pós-Graduação em Letras e Cultura, da Universidade de Caxias do Sul.

${ }^{3}$ Doutor em Estudos Literários (UFMG). Professor da Universidade Federal de Rondônia. 


\section{Abstract}

Mônica de Aquino, a poet from Belo Horizonte, has stood out in the contemporary Brazilian literature scene. In an interview granted to members of the extension project "News from Current Brazilian Literature: Interviews", which consists of a mapping of Brazilian Literature of the beginning of the 21 st century from the perspective of the writers themselves, the poet gives her account on her own creative writing process, assesses the reception of her work, and reflects upon aspects pertaining to Brazilian literature as well as upon the political and cultural framework of the latest years and the ethical response demanded by them.

Keywords: Mônica de Aquino; poetry; contemporary Brazilian literature; Brazilian children's literature; creative writing

\section{Apresentação}

Em "Alguns aspectos do conto", o escritor argentino Julio Cortázar propõe a construção de associações entre o procedimento de escrita do conto e a atenção dispensada ao enquadramento da imagem no âmbito da técnica fotográfica (CORTÁZAR, 1999, p. 351). Sob a perspectiva de Cortázar, o bom conto compreende, dentre seus pressupostos de composição, a cuidadosa delimitação de uma cena ou de um incidente que, acessados pelo leitor, conservam sua densidade ao mesmo tempo em que se abrem a uma gama de significações aventadas durante o processo de leitura.

Se por um lado a aproximação entre linguagem verbal e linguagem imagética se afigura eficaz para a reflexão sobre as propriedades centrais de um gênero literário, nos termos propostos por Cortázar, por outro pode servir ao exame de um processo de composição literária em específico. É o que se verifica na escrita 
criativa da mineira Mônica de Aquino, que, ao sugerir interlocuções entre poesia e delimitação de imagens - ou de momentos -, confere a seu texto o que se poderia tomar por uma "poética da concisão". Com efeito, o trabalho de Mônica de Aquino apresenta, dentre outros traços, a acuidade na captura de um instante, na seleção de um ponto de vista - como o de uma Penélope que dialoga com a tradição literária e, concomitantemente, manifesta particularidades - e na ressignificação de elementos extraídos das memórias de eventos vividos ou narrados por outras subjetividades.

O percurso literário de Mônica de Aquino entremeia a publicação de textos poéticos à elaboração de narrativas voltadas ao público infantil. No ano de 2005, a poeta publicou Sístole e teve seu trabalho divulgado na antologia $O$ achamento de Portugal, organizada pela Editora Anome em parceria com a Fundação Camões. Em 2009, participou da coletânea Roteiro da poesia brasileira - anos 2000, organizada por Marco Lucchesi. Em2011, Aquino publicou Fio da memória, texto de literatura infantil que foi adotado pelo programa Livros na Sala de Aula do Estado de São Paulo. Em 2013, foi contemplada com o Prêmio Cidade de Belo Horizonte por seu volume de poemas intitulado Fundo Falso e publicou Muitos jeitos de contar uma história, voltado ao público infantil. Mônica de Aquino tem seu trabalho divulgado, também, em periódicos como o Suplemento Literário de Minas Gerais e a Revista Poesia Sempre, da Biblioteca Nacional.

$\mathrm{Na}$ entrevista a seguir, realizada no âmbito do projeto de extensão "Notícia da atual literatura brasileira: entrevistas", Mônica de Aquino reflete a respeito de matizes de seu processo de composição literária e da recepção de sua obra, lança miradas ao atual cenário da poesia brasileira e compartilha com o leitor reflexões tanto a respeito do quadro político e cultural dos últimos anos quanto sobre as respostas éticas por ele demandadas. 
Cada escritor possui um modus operandi, por assim dizer. Em seu trabalho, é possível perceber uma característica marcante, a que poderíamos nos referir como uma "poética da concisão". Você poderia nos falar um pouco sobre as opções formais que norteiam seu projeto literário?

Meus poemas costumam começar num verso ou imagem que conduz a escrita. Às vezes, partem de algo que me mobiliza e fica comigo por uns dias; em outras, a origemé mais repentina. Mas sempre é a escrita do instante: quando há o convite do que já vinha sendo pensado ou vivido ou de alguma coisa que me toca, preciso escrever. Como na fotografia, em que se capta o momento. O que não contraria a concisão que se vê na minha poética: mesmo essa primeira escrita já passa por um controle, como na fotografia mesmo, em que se escolhe o ângulo, a quantidade de luz, o filtro, por vezes o tempo de observação e espera.

A busca da concisãocontinua: o principal trabalho da primeira versão até a final é cortar, limpar o que não é poesia, incluir silêncios, densificar os sentidos. Escrevo também com o corpo e dados autobiográficos estão ali, cifrados, elípticos. Não mais como mera vivência, mas como matéria de uma reescritura do afeto.

Em um dos poemas dispostos na seção "A dor como método", de Fundo Falso (2017), lê-se que José, "para curar um problema/que se fez carne, entranhado/colocava todo dia/uma pedra no sapato". Em que medida esses versos dizem de seu processo criativo?

A parte do livro que este poema abre é feita de memórias da infầncia, ou de "memórias das memórias", como esse poema que parte de recordações do meu pai que nos eram contadas de forma exemplar. O que no pai era ou é um percurso existencial, uma forma de superar a dureza das pedras cotidianas com outras pedras, voluntárias, num exercício 
ético, quero que seja em mim um exercício estético que busca, através da reescritura, ressignificar o ethos familiar.

Talvez em Fundo Falso meu processo criativo seja, em grande parte, a percepção da pedra, sua extração e burilamento - que para mim, como para o pai, é exercício de foco e aviso de perigo. Se em Sístole a água estava a todo tempo presente, em Fundo Falso a pedra é a presença. A pedra do caminho, a educação pela pedra, (título que eu adotaria se já não existisse), a reapresentação da violência e da beleza do mundo pela ótica do rigor formal. Mas que é, também, um exercício do amor, como no verso que encerra o poema.

Em Fundo falso, há uma seção intitulada "A memória das mãos", em que você retoma a imagem de Penélope por meio de uma série de poemas. Um deles é concluído com o verso "enquanto pensa: Ulisses, agora, sou eu." Parece-nos haver, nesse verso e na apresentação de uma Penélope "insone", "mentirosa", "paciente" e "urgente", um esforço voltado à promoção de diálogos entre uma memória de leitura e o presente. Em que medida essa memória de leitura é ressignificada em seu trabalho?

No caso dessa série, a referência me parece menos diretamente ligada às leituras que a um arcabouço mítico. O desejo era escrever a partir de uma personagem arquetípica, propondo visadas contemporâneas. Dialogo, por exemplo, com símbolos potentes do imaginário feminino, como a costura. Mesmo sem saber prender sequer um botão, a tessitura me dizalgo profundo, o que talvez nos levasse para o campo da psicanálise, mas não me arriscaria nele.

Borges afirma, em O ofício do verso, que há séculos três histórias têm bastado à humanidade: o Evangelho, a Ilíada e a Odisseia. A última, que traz um dos principais motivos da literatura, a viagem, é também a história de uma espera. Do papel legado à mulher por tanto tempo e que ainda 
cala em nós. Foi a leitura de Penélopes de outras poetas que me despertou para as minhas. E foi a personagem que me convidou para perto de outras figuras míticas, que seguem movendo minhaescrita.

Wislawa Szymborska é uma das autoras que me instiga a me aventurar nesse caminho, quando leio poemas como "Monólogo de Cassandra" e "A mulher de Lot". Personagens bíblicos também são do meu interesse, acho que ainda escrevo uma série a partir deles. Gosto de exercitar olhares, de recontar histórias a partir de outros pontos de vista possíveis. É o meu exercício de narrativa dentro da poesia.

\section{Como você define sua trajetória literária? Houve um momento inaugural ou o caminho se fez gradualmente? Em que momento da vida você se percebeu uma escritora?}

Geralmente, nas mesas em que participo ou que assisto, a maioria dos escritores diz que começou a escrever por causa das leituras. Falam dos livros da infância e da adolescência, muitas vezes da influência de pessoas próximas. As primeiras memórias são a biblioteca do pai, ou um tio que lia histórias, uma vizinha ou cuidadora que era uma grande contadora de casos.

Pra mim, é quase o oposto: minha escrita nasceu do silêncio, de tudo que eu não compreendia, das ausências. E também do encantamento com as palavras e com a forma de dizer da literatura. É lugar comum afirmar que a poesia “diz o indizível”. Esse interesse pelo que está além da fala e do olhar cotidiano foi o que me aproximou da poesia.

Claro que o caminho desse processo gradualà decisão de me assumir escritora implicou uma construção deliberada, iniciada na vida adulta e que envolveu pesquisa dos meus contemporâneos, contato com artistas e críticos, interlocuções que iam sendo criadas e um exercício cada vez mais consciente da leitura e da escrita. O primeiro desejo, e que continua sendo onde mais me reconheço, foi ser poeta. Há alguns anos expandi também para a literatura infantil e para parcerias que me levam a outras artes. 


\section{Além do diálogo estabelecido com Carlos Drummond de Andrade em poemas como "José adotou a dor como método", você faz referência a João Cabral de Melo Neto e à Poesia Marginal em "Não por acaso/o verso fácil" (Plaquete Cacaso não por acaso, 2009). Com que outros autores canônicos você procura estabelecer interlocuções?}

Ao adotar o nome José, sabia da possível associação com o José de Drummond. Mas o meu personagem é mais doméstico e entranhado, como já disse. Mesmo assim, sempre que me refiro à pedra, penso na pedra no caminho, no exercício cabralino de catar e separar, semesquecer de deixar no poema o grão quebra-dente. Aqui, falo de duas influências mais óbvias e gerais.

Apesar do poema em homenagem ao Cacaso, em que dialogo com o seu "verso fácil" que deseja reconhecer "todas as formas de delicadeza", não posso me dizer herdeira direta da poesia marginal e do tropicalismo.

Entre os autores que me influenciam, eu destacaria os principais nomes do modernismo e escritores que me conduzem ao equilíbrio entre texto passional e concisão, entre memória e filosofia, ludicidade e texto seco. Cito alguns: Sylvia Plath, Orides Fontela, Wislawa Szymborska, Jacques Prévert, Paulo Henriques Brito, Sophia de Mello Beyner e, saindo da poesia, Clarice Lispector, Ítalo Calvino, Amós Oz, Valter Hugo Mãe.

Diante do panorama da literatura brasileira atual, o que você vê? Que autores você tem lido? Gostaria que você nos falasse um pouco sobre suas principais inquietações e estímulos em face da produção poética brasileira contemporânea.

Vejo uma produção diversificada, que reflete diferentes tendências einfluênciase quenos leva nadireção do que se começaa chamar de "literatura expandida". A mistura de procedimentos de diferentes artes me chama a atenção, dentre elas a mescla da poesia com as artes plásticas. 
Hoje é mais fácil produzir e publicar, inclusive na internet. Infelizmente, tal facilidade, que nos tira da dependência de grandes editoras, ainda encontra o gargalo da distribuição ou da necessidade de autopromoção, a exigir outros talentos dos escritores.

Tenho lido muita teoria literária, literatura infantil e poesia contemporânea brasileira. Na poesia, as leituras de agora incluem Age de Carvalho, Mariana Ianelli, Laura Erber, Noemi Jaffe e Leila Danziger, que um amigo me apresentou recentemente. Estou encantada com o trabalho dela tanto na poesia, quanto nas artes plásticas.

Na literatura para crianças, destaco nomes como Fernando Vilela, Renato Moriconi, Roger Mello, Wolf Erlbruch, Bruno Munari, Leo Lionni, Marina Colasanti, Jutta Bauer, Odilon Moraes. Há muitos outros que admiro, a lista é longa.

Em Muitos jeitos de contar uma história (2014), você abraçou o desafio de escrever um texto literário infantil a partir de ilustrações feitas por Nelson Tunes. Após a experiência de construção de um enredo baseado em uma série de imagens que não possuíam uma ordem estabelecida, tampouco elementos identificáveis claramente (o passarinho bem poderia ser a folha de uma planta...), você percebe mudanças, em seu texto poético, quanto à maneira de pensar e criar relações entre imagem e linguagem verbal?

Minha poética já era influenciada pela imagem, mesmo que mental. Em Fundo Falso, na parte final do livro, revelo um pouco desse processo: há um poema para o Van Gogh, escrito depois de ver o filme Sonhos, do Kurosawa, e um que é uma espécie de homenagem aos irmãos Campana, dupla de designers que admiro.

Escrever Muitos jeitos talvez tenha me dado mais consciência dessa relação, me levando a refletir sobre ela. Claro, uma coisa é certa imagem, de repente, me despertar para a escrita. Outra é estar com um conjunto 
de desenhos para os quais devo escrever um texto. $\mathrm{O}$ processo foi tentar levar essa experiência do livro o mais próximo possível da escrita dos poemas e de outros textos infantis, convivendo com os desenhos até que, de certa forma, eles fossem incorporados. Convivi muito com eles antes de começar a escrever, antes de perceber os personagens ali.

Muitos jeitos de contar uma história (2014) apresenta um protagonista que convida o(a) leitor(a) a pensar a diferença. Atualmente, no Brasil e no exterior, vivemos a ascensão de uma onda reacionária que traz em si matizes racistas, fascistas, misóginos e homofóbicos. Gostaríamos que você nos ajudasse a compreender: onde estava guardada tanta monstruosidade? Houve um ponto ou marco crucial para a detonação de uma circunstância como esta que vivemos hoje? $\mathrm{O}$ que você imagina ou espera como coda do atual estágio da humanidade?

É sempre difícil analisar o momento presente. Mas arrisco algumas chaves para pensá-lo.

Achoqueparte damonstruosidadeestava escondida naintimidade. Com as redes sociais, entretanto, todos ganham palco, qualquer absurdo reverbera. Curtidas, comentários e compartilhamentos dão às pessoas uma sensação de potência, a virtualidade as protege de confrontos reais. Sentimo-nos compelidos a ter opinião sobre tudo e a nos manifestarmos. As informações são ágeis e efêmeras, as bases dos nossos pensamentos precárias. Não há tempo para a reflexão, menos ainda para o diálogo.

Junto a isso, há outro fator fundamental: a crise econômica. "Farinha pouca, meu pirão primeiro", diz o ditado. E o pouco, muitas vezes, disputamos como abutres. É hora de eleger inimigos, bodes expiatórios. Políticos como Trump ganham eleitores fomentando esse tipo de ódio. Crises ajudam a tirar da pauta pensamentos de solidariedade, abrindo espaço para disputas. Voltamà cena as polarizações, o "nós contra 
eles", que impedem as composições de interesses. É a lei da escassez que comanda; a lei do egoísmo.

Há, ainda, um terceiro ponto que não pode ser ignorado, no caso do Brasil: a mistura crescente de religião e política, no sentido contrário à laicização conquistada na modernidade. Tal retrocesso traz para a pauta discussões de caráter moralista que não deveriam dizer respeito ao coletivo, enquanto questões urgentes da esfera pública são postas de lado. Não há nada de bom que possa vir da mistura de religião com política, a história demonstra.

Por outro lado, junto a tanto retrocesso, vemos pessoas e grupos buscando reinventar a vida em sociedade. Estão mais abertos $\grave{a}$ colaboração, à construção coletiva. Acho que já não temos muito espaço para salvadores e heróis, para grandes líderes. Num mundo tão pulverizado, nossarevolução passaa ser diária, no microcosmo, nas pequenas mudanças que podemos promover no cotidiano e que começam a colocar em xeque o individualismo que o capitalismo e a tecnologia ajudaram a construir.

Quero destacar que a palavra tolerância, tão usada contra preconceitos, não me agrada muito; me parece, por vezes, mesquinha. A diversidade não está aípara ser tolerada, mas para ser valorizada, elaé uma das nossas riquezas. É ela que nos convida para fora de nós mesmos, que nos expande e engrandece o mundo. Mais do que pregar a tolerância à diferença, é fundamental ensinar sua valorização.

\section{Como você avalia a recepção de sua obra? Fale-nos um pouco sobre a recepção de sua obra poética e, também, sobre a recepção de seus textos de literatura infantil.}

Sístole, de 2005, teve uma boa repercussão, em grande parte pelo trabalho da editora. A coleção da qual o livro faz parte (Canto do Bem-tevi) foiresenhada nos principais jornais do país. Passeia ser mais conhecida, especialmente na minha cidade, e mais presente no circuito cultural. 
Mesmo sem publicar um livro de poemas por tanto tempo, continuo sendo convidada para participar de periódicos, antologias, eventos.

O "Prêmio Cidade de Belo Horizonte" de 2013 renovou o fôlego do trabalho. Mas divulgar a própria produção não é tão simples, minha presença em redes sociais ébaixa, sou uma poeta um pouco distante da cena. Nem tanto por opção; há também a dificuldade de agir de outra forma. Gostaria de ter mais interlocução, de ficar mais próxima de escritores e amigos. Sempre que sou convidada para participar de algo ou para criar um projeto ou texto, gosto muito.

$\mathrm{Na}$ literatura infantil ainda construo o meu percurso. O primeiro livro, Fio da Memória, foi adotado pelo programa Livros na Sala de Aula do Estado de São Paulo. Os outros livros ainda não contam com tantos leitores, em grande parte, acredito, por falta de divulgação e também pelo momento do país. Começar algo nesse contexto não é tão fácil. Sigo estudando e escrevendo, já tenho alguns originais guardados e outros projetos a desenvolver.

\section{Você tem participado de festivais e feiras literárias. Que avaliação crítica você faz a respeito da contribuição desses eventos para a divulgação do trabalho de novos escritores e para o fomento à leitura no país?}

Os festivais e feiras são momentos importantes de encontro, neles nascem amizades, parcerias, projetos. Temos a chance de conhecer novos autores e trabalhos, além da festa que costumam ser para quem gosta de literatura.

Mas há a questão do alcance. Sabemos que ainda se lê muito pouco no Brasil. Festivais podem ajudar, mas não podem fazer tanto onde falta educação e oportunidade. Acho muito interessante o trabalho prévio de algumas feiras, como a própria Flip, promovendo atividades voltadas para a formação de leitores, como encontros com escritores e 
oficinas paracrianças, jovenseeducadores. A feiratorna-se, assim, o ápice de um trabalho desenvolvido com os moradores das cidades que sediam os eventos. Admiro, também, feiras que saem do circuito e do modelo de sempre para aproximarem-se mais das pessoas, como a Flupp, a Festa Literária das Periferias, que a cada ano acontece em uma comunidade do Rio de Janeiro.

\section{Como você experimenta o ato de recitar? Recitar é recriar?}

Busco dizer os poemas de forma natural, dentro do que é natural no meu processo: talvez seja sempre um dizer distinto da fala cotidiana, porque passa por um outro tipo de relação com o corpo, mais visceral. Muitas vezes escrevo em pé, a atitude nunca é passiva, leio o que estou escrevendo em voz alta, me levanto, mudo a forma da leitura, sinto o ritmo, caminho, vou à cozinha, volto. Acho que essa proximidade com os poemas aparece, de alguma forma, nas vezes em que me apresento. Recitar, assim, tem algo de recriação, mas também de resgate, de encontro e abismo.

\section{No Brasil, a poesia tem um alcance bastante limitado em termos de público. Como você vê essa questão? Você acha que, no país, a poesia deixou de ocupar um lugar de destaque no debate cultural?}

Acho que o debate cultural ocorre num ambiente cada vez mais restrito. O que vale para a prosa e para as artes, em geral, mas essas têm mais alcance comercial e, consequentemente, mais visibilidade. Poesia, como vocês mesmos afirmam, tem alcance mínimo.

Além do pouco que se lê no país, atribuo o menor interesse também ao nosso atual ritmo de vida, que envolve excesso de informação, relação superficial com o conhecimento, necessidade de estímulos constantes, de "alegria" permanente e rápida, sem a disposição, de muitos, de parar e se abrir para o que pede dedicação e compromisso, como a literatura. 
As exigências do nosso tempo puxam para outras demandas, mais ligadas ao entretenimento. Nesse sentido, artistas e intelectuais perdem espaço nos debates de questões essenciais ao país, substituídos pelo imediatismo e pela lógica empresarial.

\section{Quais os principais desafios para a edição de novos escritores no Brasil de hoje?}

Um grande desafio se relaciona ao tal "alcance mínimo" de que falamos: editoras precisam vender os livrosque publicame livros de poesia não costumam ser muito comerciais.

As pequenas editoras têm papel fundamental para a poesia ao apostarememautoresquenão são conhecidos do grande público, incluindo estreantes. As tiragens costumam ser pequenas, voltadas para um grupo de leitores específico. Emregra, não há estrutura para distribuição ampla. São editoras, essencialmente, voltadas para um mercado de nicho. Corajosas, com a paixão, tantas vezes, sobrepujando o interesse econômico, ajudam a renovar a literatura.

Por outro lado, há hoje diferentes caminhos para a publicação, incluindo a internet, o que a torna mais fácil. O problema da distribuição em grande parte é superado pelos artistas que são bons no manejo das redes sociais, conseguindo construir seu espaço, chegando até leitores e interlocutores e, em alguns casos, até o mercado tradicional.

\section{Você está escrevendo algum livro no momento? Possui projetos que envolvam outros gêneros literários?}

O projeto do meu terceiro livro de poesia está bem adiantado. Afinal, estou sem publicar um livro de poemas faz tempo. Trabalho, também, em alguns originais para crianças, em verso e em prosa, além de desenvolver um trabalho a partir de fotografias de outro artista. 


\section{Referências}

AQUINO, Mônica de. Sístole. Rio de Janeiro: Bem-Te-Vi, 2005.

. Fio da memória. Ilustrações de Giselle Vargas. Belo Horizonte: Miguilim, 2011.

. Muitos jeitos de contar uma história. Il. Nelson Tunes. Belo Horizonte: Miguilim, 2013.

. Fundo Falso. Belo Horizonte: Miguilim, 2017 (no prelo).

CORTÁZAR, Julio. Alguns aspectos do conto (1962-1963). In: Obra crítica. Volume2. Org. Jaime Alazraki. Trad. Paulina Wachte Ari Roitman. Rio de Janeiro: Civilização Brasileira, 1999. 


\section{Anexo: Poemas de Mônica de Aquino}

\section{Penélope mentirosa}

De noite desfaz, obediente

a fera que a carne abriga

e regressa à partida: a espera indefinida.

De dia, é outro o desejo

tece a mortalha com o silêncio

de ter de casar-se outra vez

(presa entre duas promessas)

mas Penélope mente: o que quer é a solidão.

A fidelidade é um cão. 


\section{A dor como método}

Para vencer um problema

que se fez carne, entranhado

colocava todo dia

uma pedra no sapato

assim mesmo, sem metáforas

ou meios-termos: era homem de atos.

A dureza da pedra - e da técnica

mantinha em José o foco

a alma sóbria

a mínima cicatriz como aviso.

(O homem, ainda jovem

habitou o calor do norte

e teve amigo matador

do tipo que extirpa o mal

pela raiz:

decepou o próprio dedo

para vencer o gatilho.)

Aos poucos a pedra gasta

ao corpo assimilada

fez-se pele sangue lastro

um árduo aprendizado:

a perfeição do rigor.

No exercício de amor. 


\section{O efeito da quebra}

O inseto na janela não entende a transparência.

Debate-se, não sabe o vidro da impossibilidade.

Fere-se a cada tentativa, sem descobrir se há vida

em outra saída, de emergência.

Para quem passa, o inseto é transparente

um gesto assim, sem eloquência, quem poderia ver?

Talvez um ferrão, o veneno, qualquer incômodo

mas as asas e o silêncio são vidro sem objeto

só se conheceria o efeito da quebra.

Enfrentando, assim, a janela, em breve ele irá morrer.

As asas, então, vão cair sobre o aparador

"são tão bonitas", alguém vai dizer, e a morte merecerá o cuidado

que não coube à vida.

As asas serão guardadas em um livro fechado, até que sobreviva apenas, o pó de uma metáfora.

Antes a janela vai ser, inutilmente, aberta. 


\section{Matéria bruta}

depois de Sonhos, de Kurosawa

O que jaz perfeito como um retrato não serve para a pintura.

É preciso a tessitura do erro o toque de um disfarce

captar-se em toda luz sob o desterro o voo torto do corvo, talvez o brilho da noite.

A vida que se arremessa como locomotiva em desespero para reter o encanto

repetir-se e repetir-se até ter em si

o quadro, inteiro, como nova natureza.

É preciso incorporar paisagem à pele atravessar a ponte percorrer o campo saber da loucura o canto da sereia ou arrancar as orelhas seduzir-se por qualquer forma de beleza, e ser preciso até que de si reste apenas um girassol sob um sol implícito.

Fonte: AQUINO, Mônica de. Fundo Falso. Belo Horizonte: Miguilim, 2017 (no prelo). 